\title{
Testes Imediatos em Doentes com Eczema das Mãos
}

\author{
João Azevedo', Frederico Regateiro', Miguel Gouveia², Leonor Ramos², Margarida Gonçalo2,3 \\ 'Serviço de Imunoalergologia, Centro Hospitalar e Universitário de Coimbra, Coimbra, Portugal \\ ${ }^{2}$ Serviço de Dermatologia, Centro Hospitalar e Universitário de Coimbra, Coimbra, Portugal \\ ${ }^{3}$ Faculdade de Medicina da Universidade de Coimbra, Coimbra, Portugal
}

RESUMO - Introdução: O eczema das mãos é uma doença multifactorial onde, muitas vezes, coexistem dermatite atópica, dermatite de contacto irritativa, dermatite de contacto alérgica (mediada principalmente pelas células T) e ainda reacções imediatas, como ocorre na urticária de contacto e/ou dermatite de contacto por proteínas (mediada ou não por lgE). O objectivo do estudo foi a caracterização dos doentes com eczema das mãos que reportaram sintomas imediatos com o manuseamento de produtos diversos. Material e Métodos: Análise retrospectiva dos registos dos doentes do Serviço de Dermatologia com eczema das mãos que realizaram testes epicutâneos e testes cutâneos por picada. Os testes epicutâneos englobaram as séries básica europeia/portuguesa e séries complementares, seleccionadas de acordo com os antecedentes clínicos. Os testes cutâneos por picada foram realizados sempre que os doentes referiam sintomas imediatos com a exposição, e foram correlacionados com IgE específica e total. Resultados: Foram avaliados 52 doentes (49F/3M), média de idades: 33,4 \pm 9,9 anos, 25 (48,1\%) com antecedentes pessoais de atopia (nove com dermatite atópica). Além do eczema das mãos, considerado ocupacional em 33 doentes (63,5\%), a dermatite também envolveu a face em seis doentes (11,5\%). Foram observados testes epicutâneos positivos em 31 doentes $(59,6 \%)$, principalmente ao níquel $(14 ; 45,2 \%)$. Verificaram-se testes cutâneos por picada positivos em 28 doentes $(53,8 \%)$, principalmente para o látex $(10 ; 35,7 \%)$, seguido de kiwi $(8 ; 28,6 \%)$. Não houve correlação estatisticamente significativa entre os testes cutâneos por picadapositivos e a presença de atopia ou de lgE sérica total elevada. Conclusão: Embora o estudo inclua um número limitado de doentes com eczema das mãos e apenas tenham sido realizados testes cutâneos por picada naqueles com história sugestiva, observaram-se reacções imediatas relevantes numa percentagem muito significativa de doentes (53,8\%), principalmente naqueles com antecedentes pessoais de atopia. A lgE específica não foi útil para o diagnóstico, face aos testes cutâneos por picada. Reacções imediatas, não directamente dependentes de células T, podem estar significativamente envolvidos na patogénese do eczema das mãos, pelo que os testes imediatos devem ser mais frequentemente adicionados aos testes epicutâneos no estudo do eczema das mãos.

PALAVRAS-CHAVE - Dermatoses da Mão; Eczema; Testes Cutâneos; Testes Epicutâneos.

\section{Immediate Test Reactions in Hand Eczema}

ABSTRACT - Introduction: Hand eczema is a multifactorial disease that can include manifestations of atopic dermatitis, irritant contact dermatitis, allergic contact dermatitis (mediated mainly by $T$ cells) and/or immediate reactions such as contact urticaria or protein contact dermatitis (mediated or not by lgE). The study aim was the characterization of patients with hand eczema who reported immediate symptoms with the handling of suspected triggers. Material and Methods: Retrospective analysis of medical records of patients from the Dermatology Department with hand eczema who performed patch tests (baseline and complementary series according to the clinical history) and skin prick test whenever patients presented immediate symptoms with suspected triggers. Skin prick test results were correlated with specific and total IgE. Results: A total of 52 patients were evaluated (49F/3M), mean age: $33.4 \pm 9.9$ years, 25 (48.1\%) with a personal history of atopy (nine with atopic dermatitis). Besides hand eczema, considered occupational in 33 patients (63.5\%), dermatitis also involved the face in six (11.5\%). We found positive patch tests in 31 patients (59.6\%), mainly to nickel (45.2\%). Skin prick test were positive in 28 patients (53.8\%), mainly for latex (10, 35.7\%) and kiwi $(8,28.6 \%)$. There was no statistically significant correlation between positive skin prick test and the presence of atopy or

Correspondência: João Azevedo

Serviço de Imunoalergologia

Centro Hospitalar e Universitário de Coimbra

Praceta Mota Pinto, 3000-075 Coimbra, Portugal

E-mail: jplazvdootmail.com

DOI: https://dx.doi.org/10.29021/spdv.76.2.896
Recebido/Received

31 Janeiro/January 2018

Aceite/Accepted

06 Março/March 2018 
high total serum IgE. Conclusion: Although the study included a limited number of patients with hand eczema and we only performed skin prick test in those with complaints, we observed immediate reactions in a very significant proportion of patients (53.8\%), mainly in the atopic group. Specific IgE was not useful for the diagnosis, compared to the skin prick test. Immediate mechanisms, not directly dependent on T cells, may be significantly involved in the pathogenesis of hand eczema, so immediate tests should be added more often to patch tests in the study of hand eczema.

KEYWORDS - Eczema; Hand Dermatoses; Patch Tests; Skin Tests.

\section{INTRODUÇ̃̃O}

O eczema das mãos (EM) é uma doença multifactorial, em que, frequentemente, coexiste dermatite atópica das mãos, dermatite de contacto irritativa, dermatite de contacto alérgica (mediada por células T) e ainda sintomas imediatos (urticária de contacto e/ ou dermatite de contacto por proteínas (DCP)), dependentes ou não de lgE específica do alergénio.'

No que concerne aos mecanismos de urticária de contacto, estes dividem-se em não-imunológicos, imunológicos e incertos. As queixas surgem habitualmente minutos após a exposição e desaparecem quando o agente agressor (alergénio ou irritante) é removido. Existem 4 estadios consoante as manifestações reportadas: 1: urticária localizada, 2: urticária generalizada, 3: urticária, asma e rinoconjuntivite e 4: urticária e anafilaxia. As principais profissões de risco associadas à urticária de contacto são os trabalhadores da indústria alimentar, incluindo os que manipulam vegetais, frutas, peixes, mariscos, carnes. ${ }^{2,3}$ Até há algum tempo os trabalhadores da saúde eram considerados aqueles com maior risco de desenvolverem reacções tipo 1, nomeadamente urticária de contacto, asma e anafilaxia, decorrentes da alergia ao látex, com prevalências de $1 \%$ a $40 \%$, consoante a população estudada e os métodos de investigação usados. ${ }^{4-6}$ Posteriormente, no âmbito dos trabalhadores da saúde, tem sido estudada a relação entre reacções imediatas e tardias com o eczema das mãos e outros alergénios além do látex, como a clorexidina e o óxido de etileno. ${ }^{7}$

A dermatite de contacto por proteínas foi descrita em 1976 por Hjorth e Roed-Petersen para descrever casos de trabalhadores com eczema das mãos e antebraços com queixas imediatas após contacto com alergénios proteicos em pele previamente lesada. ${ }^{8}$ A patogénese da dermatite de contacto por proteínas não está inteiramente esclarecida, mas a presença de lgE específicas nas células apresentadoras de antigénio da pele poderá facilitar a sensibilização e activação de linfócitos T.9

Ainda que a clínica se assemelhe a dermatite de contacto alérgica, os resultados dos testes epicutâneos (Tep) são por norma negativos, enquanto os testes cutâneos por picada (TCp) são positivos.10 A histologia, por seu lado, é a característica da dermatite de contacto alérgica ou de

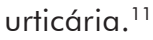

O diagnóstico baseia-se na história clínica e nos testes cutâneos de contacto ou por prick. O prognóstico é bastante variável. ${ }^{12-14}$

Existem poucos estudos que correlacionem o eczema das mãos e a presença de reacções imediatas.
Com este trabalho, pretendeu-se caracterizar do ponto de vista alergológico os doentes com eczema das mãos que reportaram sintomas imediatos com o manuseamento de distintos produtos.

\section{MATERIAL E MÉTODOS}

Foi feito levantamento e análise retrospectiva dos doentes com eczema das mãos, que realizaram TEp e TCp entre 2007 e 2015 no Serviço de Dermatologia do Centro Hospitalar e Universitário de Coimbra (CHUC).

Os TEp utilizados englobaram a série básica adoptada pelo grupo Português de Estudo de Dermatites de Contacto (GPEDC), acrescida de alguns alergénios, assim como de outras séries seleccionadas de acordo com a exposição e com a localização da dermatite. Os TEp foram aplicados no dorso (dia zero - D0) em câmaras Finn ${ }^{\circledR}$ de $8 \mathrm{~mm}$ em adesivo Scanpor ${ }^{\circledR}$ (Epitest, Ld Finnland), a oclusão mantida por 2 dias e as leituras realizaram-se em D2 ou D3 e entre D4 e D7 para avaliar respostas mais tardias ou no caso de reacções não esclarecedoras ou duvidosas. Os resultados foram interpretados como positivos de acordo com os critérios do ICDRG (International Contact Dermatitis Research Group), e as normas da ESCD (European Society of Contact Dermatitis). ${ }^{15,16}$

Os TCp foram realizados sempre que os doentes referiram queixas imediatas, utilizando um controlo positivo (histamina $10 \mathrm{mg} / \mathrm{mL}$, Bial-Aristegui ${ }^{\circledR}$ ), um controlo negativo (solução salina 0,9\%), látex (Bial-Aristegui ${ }^{\circledR}$ ) ou outros desencadeantes suspeitos, principalmente alimentos frescos ou congelados em fresco e descongelados mesmo antes da realização dos testes. Nestes casos, procedeu-se ao método prick-to-prick, onde o alimento ou alergénio em questão é "picado" e, de seguida, é feita uma picada na pele da face antero-interna do antebraço do doente com a mesma lanceta impregnada no alergénio. Um fragmento do alergénio é colocado sobre a área da picada durante cerca de 10 minutos e as leituras efectuadas aos 20 minutos (Fig. 1). Foram consideradas reacções positivas as que revelaram uma pápula de diâmetro médio igual ou superior a $3 \mathrm{~mm}$, em relação ao controlo negativo. Em alguns doentes foram, ainda, doseadas a lgE total e lgE específicas, de acordo com a positividade dos TCp. Foram avaliadas as características demográficas, a presença de atopia, os aspectos clínicos das lesões cutâneas e a correlação entre os resultados dos testes e, sempre que disponível, os dados laboratoriais. Foi feita análise estatística dos dados, recorrendo ao programa SPSS, versão 22.0. 


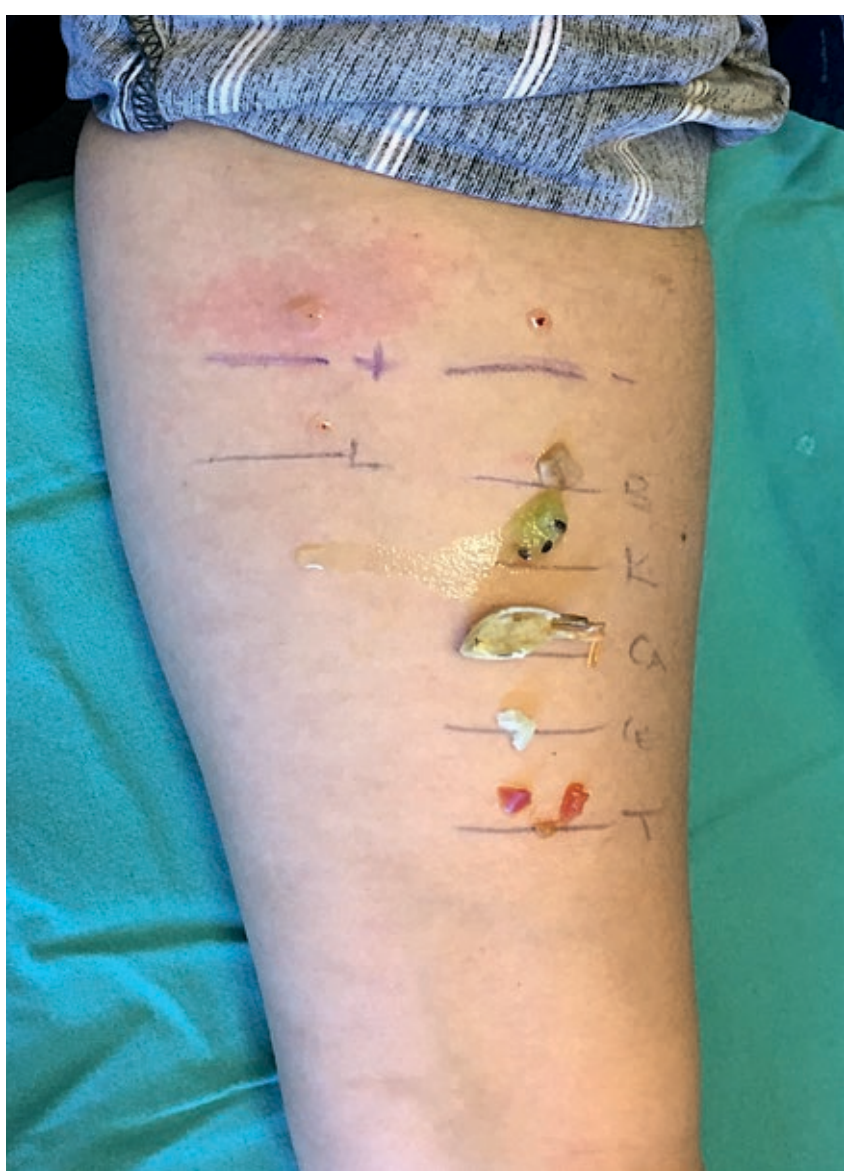

Figura 1 - Exemplificação dos testes cutâneos por picada (TCp) pelo método prick-to-prick e de contacto.

\section{RESULTADOS}

Foi obtida uma amostra de 52 doentes com EM e sintomas imediatos, 49 do sexo feminino, três do sexo masculino. A média de idades foi de 33,4 \pm 9,9 anos, entre o mínimo de 19 anos e o máximo de 54 anos. Dos doentes analisados, 25 tinham antecedentes pessoais de atopia $(48,1 \%)$, dos quais nove com dermatite atópica, mas em nenhum dos casos houve referência a sintomas respiratórios com a exposição aos alergénios suspeitos e apenas uma doente referiu sintomas digestivos com a ingestão de camarão.

O EM evoluía em média desde há 4,1 \pm 3,5 anos (6 meses-20 anos), envolvia também o punho e/ou antebraços em sete doentes $(13,5 \%)$ e associava-se a lesões da face em seis $(11,5 \%)$. De acordo com o questionário, as queixas estavam relacionadas com a actividade ocupacional em 33 doentes $(63,5 \%)$.

Os TEp foram positivos em 31 doentes $(59,6 \%)$ principalmente para o níquel (14 doentes - 26,9\%); seguido de conservantes (isotiazolinonas, timerosal, formaldeído e metildidromoglutaronitrilo) em 12 doentes - 23,1\%; alergénios da borracha, sobretudo os tiurans, em oito doentes - 15,4\%; perfumes (mistura de fragâncias I e II e Myroxylon

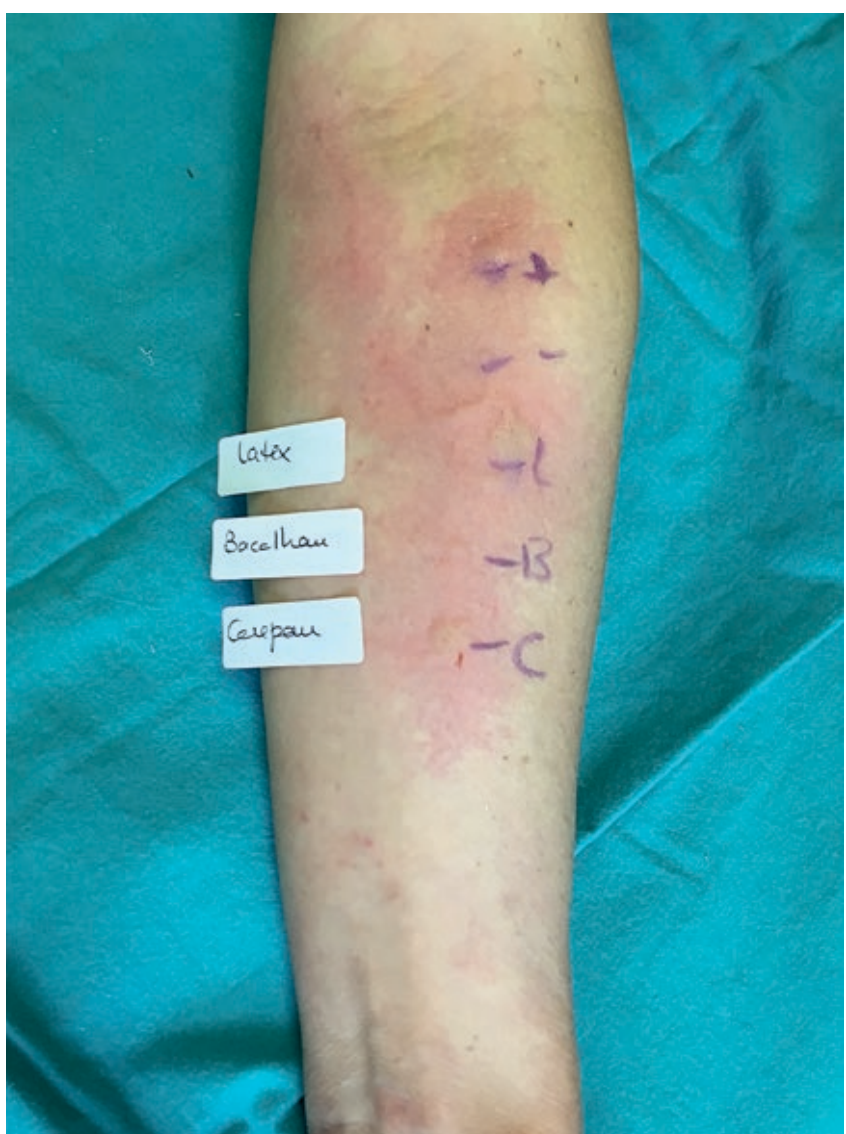

Figura 2 - Resultados dos TCp com controlo positivo (histamina), negativo (solução salina), extracto comercial de látex e testes prick-ło-prick com bacalhau e carapau (doente 16).

pereirae) em seis doentes - 11,5\% e alimentos, nomeadamente o dissulfureto de dialilo (alergénio do alho) em três doentes $(5,8 \%)$ e a cenoura em um doente $(1,9 \%)$.

Os TCp foram positivos em 28 doentes (53,8\%), 15 dos quais atópicos (53,6\%), 4 com dermatite atópica (Fig. 2). Os alergénios mais frequentemente implicados foram: látex: 10; kiwi: 8: moluscos e camarão: 5; tomate: 4; batata: 4; peixe: 3 e farinhas: 3 .

Os TCp foram considerados profissionais em 17 doentes $(17 / 28-60,7 \%)$, sendo as seguintes as profissões mais envolvidas: cozinheiras/ajudantes de cozinha (6), enfermagem (4), padeiros/pasteleiras (3), operárias fabris (2), taIhante (1) e trabalhadora com iscos de pesca (1) (Tabela 1). Nos restantes 11 doentes $(39,3 \%)$ os testes positivos não resultaram de exposição profissional (Tabela 2 ).

Os restantes doentes, cujos TCp foram negativos, estão descriminados na Tabela $3(n=24)$. Desses, 16 foram considerados ocupacionais pelo agravamento inequívoco com a exposição laboral e pela reactividade nos TEp.

De um total de 32 doentes a quem foi feito o doseamento da $\lg$ E sérica total, verificou-se que $17(53,1 \%)$ tinham valores de lgE total superiores a $100 \mathrm{kU} / \mathrm{L}$, média de 534,8 kU/L (124-2330 kU/L). 


\section{GPDEC}

Tabela 1 - Características dos doentes com Eczema das mãos e testes imediatos positivos relacionados com a actividade profissional $(\mathrm{N}=17)$. Alergénios responsáveis e valores de lgE total e específica.

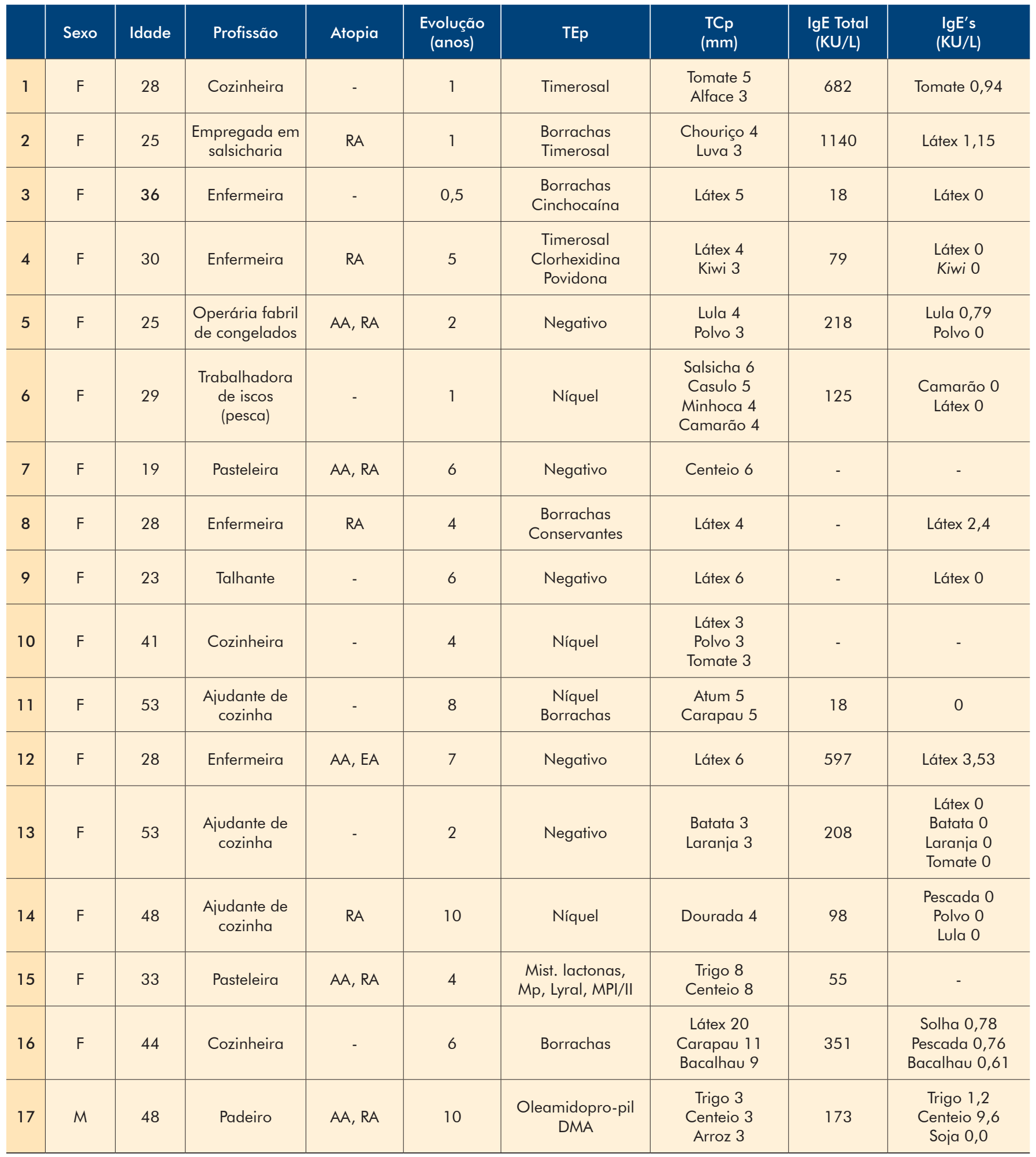


Tabela 2 - Características dos doentes com Eczema das mãos e testes imediatos positivos sem relação com a actividade profissional $(\mathrm{N}=11)$. Alergénios responsáveis e valores de lgE Total e específica.

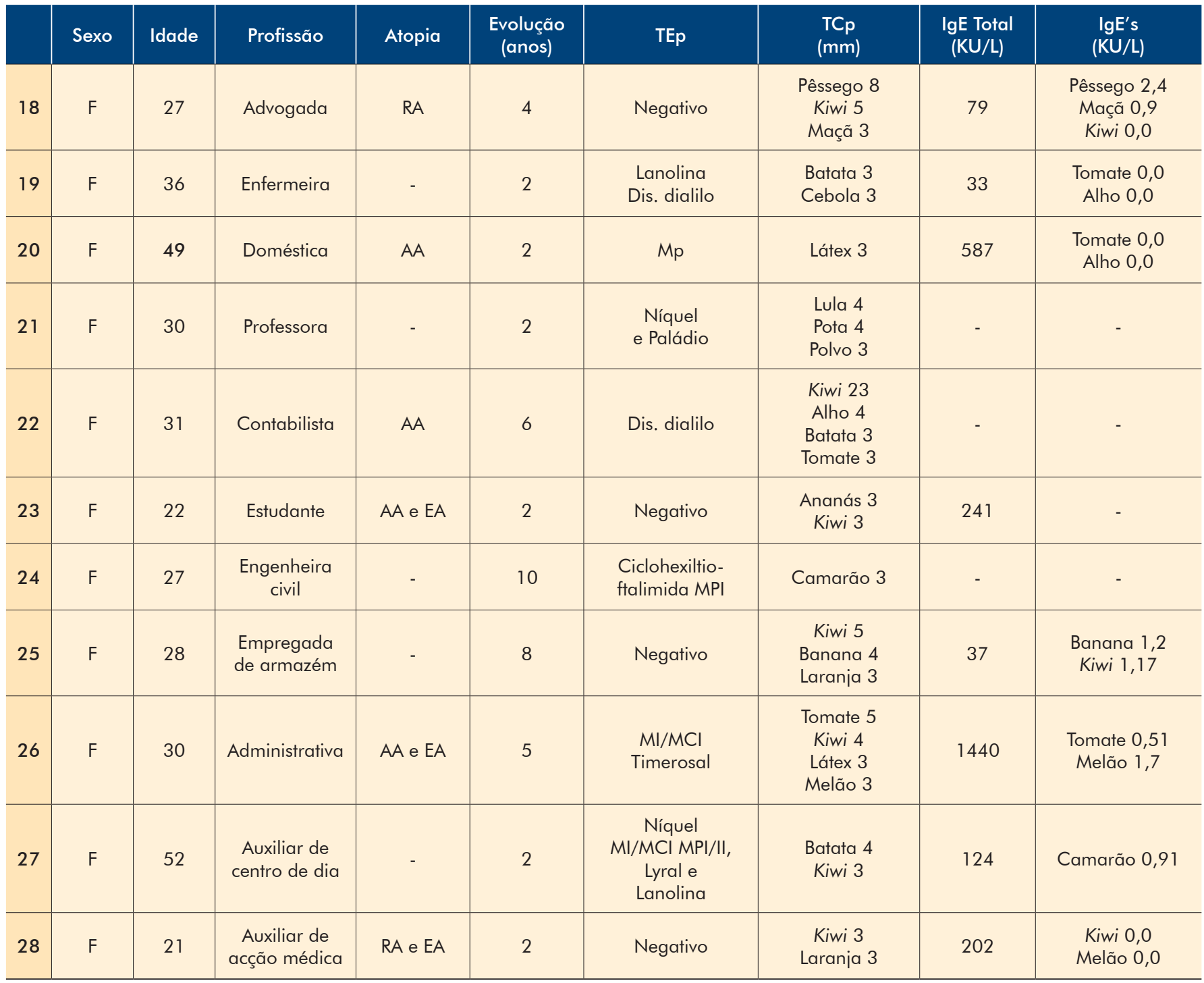

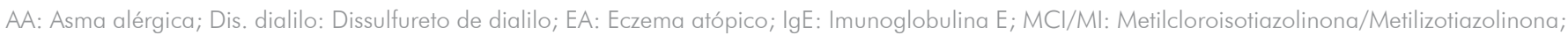
Mp: Myroxylon pereirae; MPI/II: Mistura de Perfumes I e II. RA: Rinite alérgica; TCp: Testes cutâneos por picada; TEp: Testes epicutâneos.

Dos 33 doentes em que se dosearam lgE específicas, $11(33,3 \%)$ obtiveram resultados positivos $(>0,70 \mathrm{kU} / \mathrm{L}$ ou classe II), todos em concordância com o TCp, nomeadamente em casos do látex, de peixes e mariscos, cereais e tomate. No entanto, em três doentes com TCp positivo ao látex não se identificaram IgE específicas e houve ainda discordância entre o $\mathrm{TCp}$ imediato positivo e a respectiva $\lg \mathrm{E}$ específica em outros sete casos, quatro dos quais relacionados com o kiwi. Não se verificaram lgE específicas positivas para alergénios com TCp negativos (Tabelas 1, 2 e 3).

Da análise estatística realizada, não se verificou correlação estatística significativa entre os TCp positivos e a presença de atopia ou elevação da lgE total sérica.

\section{DISCUSSÃO}

Este é um dos maiores estudos entre nós com identificação de alergénios variados provocando reacções imediatas em relação com eczema das mãos. O látex mantém-se como alergénio frequente, mas em declínio, tal como reportado por Poole et al. ${ }^{17}$ Três dos doentes com TCp positivos ao látex (extracto comercial) tiveram um doseamento negativo de lgE específica do mesmo, pelo que podemos inferir que os TCp revelaram ter maior sensibilidade que o estudo analítico, como já tinha sido demonstrado em estudos anteriores. ${ }^{18}$ Outros alergénios surgem com percentagens elevadas, ainda que dependam obviamente da exposição a que muitos dos doentes/ trabalhadores estão sujeitos. 


\section{GPDEC}

Tabela 3 - Características dos doentes com Eczema das mãos e testes imediatos negativos, apesar das queixas imediatas ( $\mathrm{N}=24)$. Alergénios responsáveis e valores de lgE Total e específica.

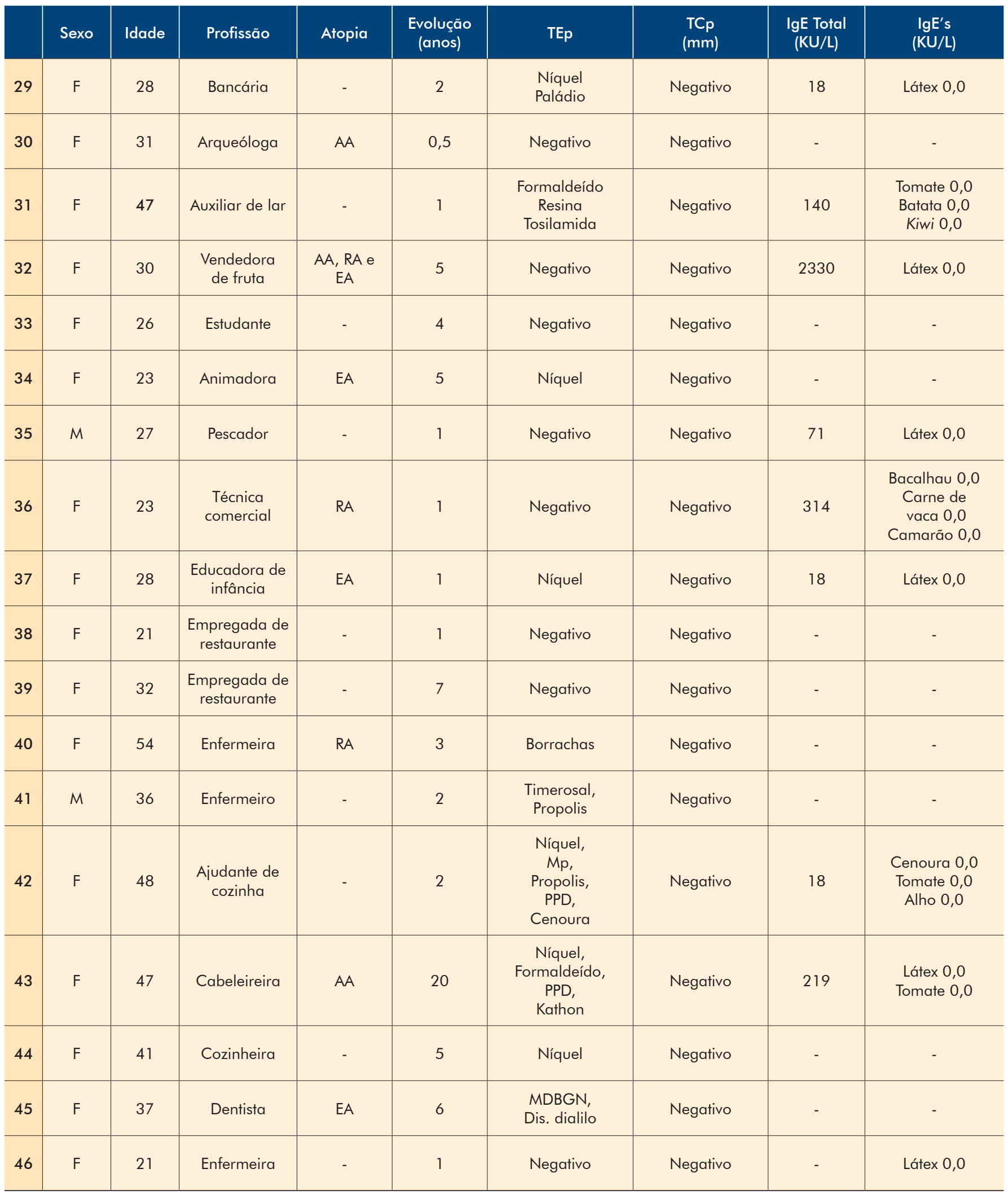




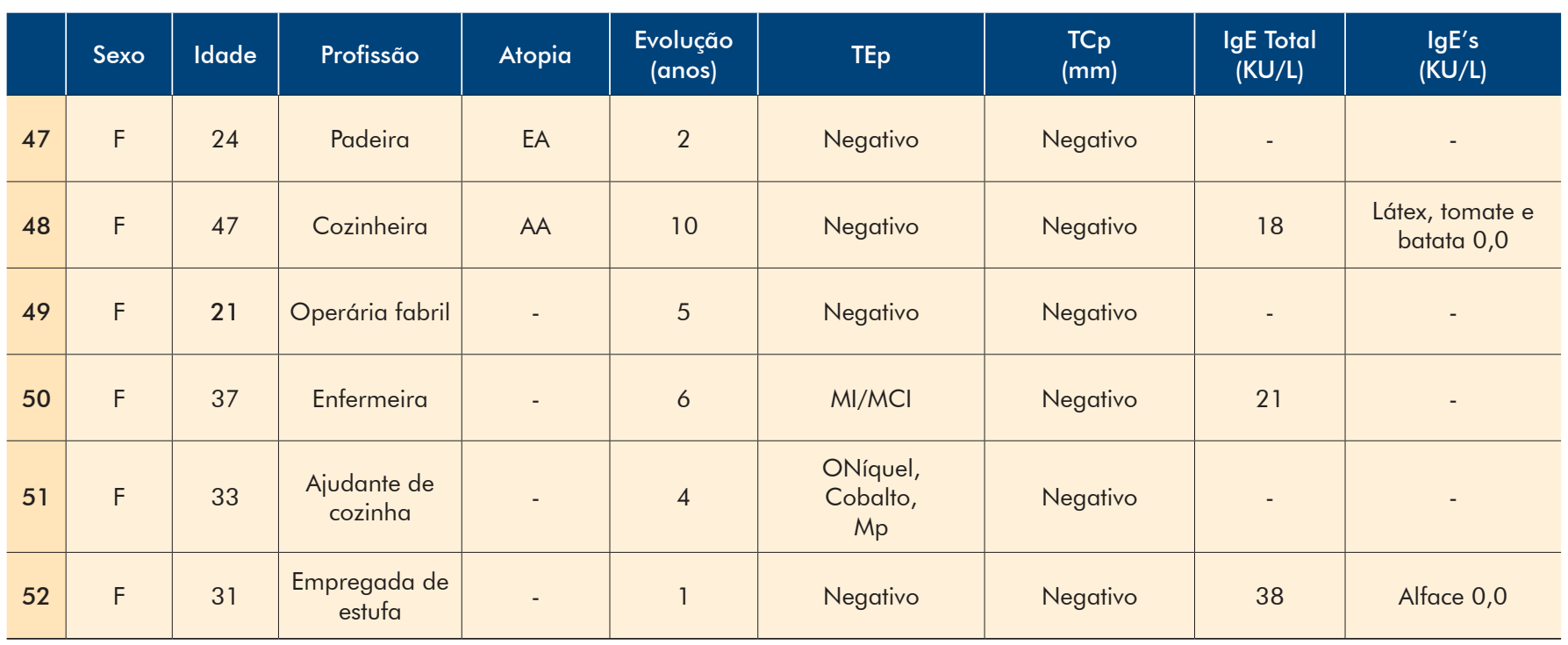

AA: Asma alérgica; Dis. dialilo: Dissulfureto de dialilo; EA: Eczema atópico; IgE: Imunoglobulina E; MCl/MI: Metilcloroisotiazolinona/Metilizotiazolinona; Mp: Myroxylon pereirae; MPI/II: Mistura de Perfumes I e II. RA: Rinite alérgica; TCp: Testes cutâneos por picada; TEp: Testes epicutâneos.

No caso dos alimentos, os alergénios mais frequentemente envolvidos, nomeadamente frutos, vegetais e peixes, vão de encontro ao de uma revisão sistemática publicada em 2016 sobre urticária de contacto profissional. ${ }^{12}$

Nestes casos, além das reacções imediatas com prurido e/ou alterações urticariformes, o contacto com as mãos muitas vezes previamente lesadas ocasionam quadros de dermatite de contacto por proteínas, em que a manifestação clínica mais comum acaba por ser a de um eczema crónico ou recorrente das mãos, punhos e/ou antebraços, com episódios de prurido e vesículas que surgem pouco após o contacto com os desencadeantes. ${ }^{19}$

No que respeita à comparação entre os TCp positivos e o doseamento de lgE específicas aos respectivos alimentos a disparidade é ainda maior do que face ao látex, facto justificável pela ausência de proteínas presentes num extracto comercial, comparativamente ao alimento na natureza. $\bigcirc$ valor da lgE total também não mostrou correlação nos doentes cujos TCp foram positivos pelo que, podemos depreender que a sua elevação se encontra intimamente relacionada com outras doenças alérgicas, nomeadamente respiratórias, e não directamente com as queixas cutâneas.

Os autores pretendem também ressalvar as consequências da sensibilização a alergénios alimentares com o risco de progressão para sintomas sistémicos e o perigo potencial de anafilaxia. Ainda, o facto de todos os doentes se encontrarem em idade laboral activa constitui certamente um problema de saúde pública pois, em muitos casos, a evicção no trabalho pode não ser completa e eficaz, condicionando assim a mudança do posto de trabalho. ${ }^{20}$

Nos casos em que aparentemente não foram identificados alergénios que justifiquem as queixas referidas pelos doentes, podem estar envolvidos agentes irritativos (químicos ou físicos), que causem dano directo na camada córnea, já habitualmente fragilizada, sobretudo nos indivíduos com dermatite atópica. A inflamação gerada, mesmo não desencadeada por alergénios e perpetuada ao longo do tempo, permite a evolução para quadros de eczema crónico e, secundariamente, ao facilitar a penetração de alergénios proteicos de maiores dimensões poderá favorecer a sensibilização nestes doentes.

Como limitação deste estudo retrospectivo em doentes reais, não se conseguiram apurar todos os extractos por prick ou por doseamento de lgE específicas. O carácter crónico e a terapêutica tópica, por vezes pouco eficaz, tornam difícil a adesão dos doentes ao seguimento em consultas, pelo que, alguns ficaram com o estudo incompleto. No entanto, na maioria dos doentes, verificou-se uma melhoria significativa do EM após cumprimento das medidas de evicção dos alergénios com resultado positivo nos testes.

\section{CONCLUSÃO}

Embora este estudo inclua um número reduzido de doentes com EM e apenas naqueles com história positiva se tenham realizado $\mathrm{TC} p$, observaram-se reacções imediatas numa percentagem significativa dos doentes testados $(53,8 \%)$, muitos deles com antecedentes pessoais de atopia. A lgE específica não contribuiu para o diagnóstico tendo em conta que apresentou uma sensibilidade inferior, comparativamente aos testes cutâneos.

A questão ocupacional é de especial relevo, pois trabaIhadores com eczema das mãos acabam por estar mais expostos a potenciais alergénios. Com uma barreira cutânea já fragilizada e contacto repetitivo, a sensibilização, nomeadamente a alergénios proteicos, torna-se mais facilitada.

A contribuição de mecanismos imediatos, não dependentes da participação clássica do linfócito T na dermatite de contacto alérgica, pode estar verdadeiramente 
subjacente à patogénese de muitos casos de EM pelo que os testes imediatos, por prick ou apenas com o contacto, devem ser mais frequentemente adicionados à técnica dos testes epicutâneos no estudo do eczema das mãos.

Conflitos de interesse: Os autores declaram não possuir conflitos de interesse.

Suporte financeiro: $O$ presente trabalho não foi suportado por nenhum subsídio ou bolsa.

Confidencialidade dos dados: Os autores declaram ter seguido os protocolos do seu centro de trabalho acerca da publicação dos dados de doentes.

Protecção de pessoas e animais: Os autores declaram que os procedimentos seguidos estavam de acordo com os regulamentos estabelecidos pelos responsáveis da Comissão de Investigação Clínica e Ética e de acordo com a Declaração de Helsínquia da Associação Médica Mundial

Conflicts of interest: The authors have no conflicts of interest to declare.

Financing Support: This work has not received any contribution, grant or scholarship.

Confidentiality of data: The authors declare that they have followed the protocols of their work center on the publication of data from patients.

Protection of human and animal subjects: The authors declare that the procedures followed were in accordance with the regulations of the relevant clinical research ethics committee and with those of the Code of Ethics of the World Medical Association (Declaration of Helsinki).

\section{REFERÊNCIAS}

1. Halling-Overgaard AS, Zachariae C, Thyssen JP. Management of atopic hand dermatitis. Dermatol Clin. 2017;35:365-72.

2. Esser PR, Martin SF. Pathomechanisms of contact sensitization. Curr Allergy Asthma Rep. 2017;17:83.

3. Wiszniewska M, Walusiak-Skorupa J. Recent trends in occupational contact dermatitis. Curr Allergy Asthma Rep. 2015;15:43.

4. Turjanmaa K. Incidence of immediate allergy to latex gloves in hospital personnel. Contact Dermatitis. 1987; 17:270-5.

5. Smedley J, Jury A, Bendall H. Prevalence and risk factors for latex allergy: a cross sectional study in a UK study. Occup Environ Med. 1999;56:833-6.

6. Filon FL, Bosco A, Fiorito A. Latex symptoms and sensitization in health care workers. Int Arch Occup Environ
Health. $2001 ; 74: 219-23$.

7. Ibler KS, Jemec GB, Garvey LH, Agner T. Prevalence of delayed-type and immediate-type hypersensitivity in healthcare workers with hand eczema. Contact Dermatitis. 2016;75:223-9.

8. Hjorth N, Roed-Petersen J. Occupational protein contact dermatitis in food handlers. Contact Dermatitis. 1976;2:28-42.

9. Bruynzeel-Koomen C, Van Wichen DF, Toonstra J, Berrens $\mathrm{L}$, Bruynzeel PL. The presence of IgE molecules on epidermal Langerhans cells in patients with atopic dermatitis. Arch Dermatol Res. 1986;278:199-205.

10. Lahti A. Nonimmunologic contact urticaria In: Amin S, Lahti A, Maibach HI, editors. Contact urticaria syndrome. New York: CRC Press; 1997.p.5-10.

11. Kanerva L, Pajari-Backas M. IgE-mediated RAST negative occupational protein contact dermatitis from taxonomically unrelated fish species. Contact Dermatitis. 1999;41:295-6.

12. Lukács J, Schliemann S, Elsner P. Occupational contact urticaria caused by food - a systematic clinical review. Contact Dermatitis. 2016;75:195-204.

13. Hernández-Bel P, Cuadra J, García R, Alegre V. Protein contact dermatitis: review of 27 cases. Actas Dermosifiliogr. $2011 ; 102: 336-43$.

14. Sasseville D. Occupational contact dermatitis. Allergy Asthma Clin Immunol. 2008;4:59-65.

15. Bruze M, Conde-Salazar L, Goossens A, Kanerva L, White IR. Thoughts on sensitizers in a standard patch test series. Contact Dermatitis. 1999;41:241-50.

16. Beck $M H$, Wilkinson SR. Contact dermatitis: Allergic. In: Burns T, Breathnach S, Cox N, Griffiths C, editors. Rook's Textbook of Dermatology. 8th ed. Oxford: Wiley-Blackwell; 2010.p.84-99.

17. Poole CJM, Nagendran V. Low prevalence of clinical latex allergy in UK health care workers: a cross-sectional study. Occup Med. 2001;51:510-2.

18. Pridgeon C, Wild G, Ashworth F. Assessment of latex allergy in a healthcare population: are the available tests valid?. Clin Exp Allergy. 2000;30:1444-9.

19. Amaro C, Goossens A. Immunological occupational contact urticaria and contact dermatitis from proteins: a review. Contact Dermatitis. 2008;58:67-75.

20. Carøe TK, Niels E, Ebbehøj NE, Agner T. Occupational hand eczema and/or contact urticaria: factors associated with change of profession or not remaining in the workforce. Contact Dermatitis. 2018;78:55-63. 